\title{
Impact of Personality Traits and Socio-Demographic Factors on Depression among Doctors and Nurses
}

\author{
Maya Thapasya \\ Department of Psychology, Heriot-Watt University, Al Sufouh, Knowledge Park, Dubai, UAE \\ *Corresponding Contact: \\ Email: mayathapasya@gmail.com
}

Manuscript Received: 14 Dec 2021

Accepted: 18 Jan 2022

\begin{abstract}
The workplace is not immune to conflict and stress, specifically when fulfilling people's responsibilities at great personal costs. Doctors and nurses are always on the frontline in hospitals, vaulting from one stressful high-stakes situation to the next. The HEXACO model of personality traits: Honesty-humility, Emotionality, Extraversion, Agreeableness, Conscientiousness, and Openness, has long been hypothesized to be a major predicting factor when determining individuals' responses to stress and susceptibility to experiencing depression. Most research suggests that personality traits resonate with a person's cognitive abilities and how they can deal with stress and depression. However, there is a lack of research on their correlation to depression severity in the Middle East. The current study aimed to investigate the impact of HEXACO personality traits and socio-demographic factors on depression amongst doctors and nurses. A sample of 170 doctors and nurses (62.1\% doctors) completed HEXACO-60 and PHQ-9 depression severity questionnaires. The data were analyzed through descriptive statistics, independent samples t-test, ANOVA, correlation, and regression analysis. The findings showed that Honesty-humility was the strongest predictor, while extraversion was the second strongest. Emotionality had the least impact on depression. The relationship between Agreeableness and Openness to Experience with depression was insignificant. However, gender, age, working hours, and work experience were significant predictors of depression. Marital status and level of specialization were insignificant predictors. Thus, it was concluded that not all HEXACO traits and socio-demographics predict depression. Study findings could be utilized in the implementation of employee recruitment, job crafting, positive psychology, and coaching.
\end{abstract}

Keywords: HEXACO Personality Traits, Socio-demographic Factors, Depression Severity

This article is is licensed under a Creative Commons Attribution-NonCommercial 4.0 International License.

Attribution-NonCommercial (CC BY-NC) license lets others remix, tweak, and build upon work non-commercially, and

although the new works must also acknowledge \& be non-commercial.

\section{INTRODUCTION}

Depression is among the most urgent yet underappreciated population health problem worldwide (Abraham et al., 2021). Globally, depressive disorders are a primary cause of years of life lost due to disability (Wang et al., 2016). Between 1990 and 2017, analysis results of the Global Burden of Disease data revealed a $49.86 \%$ increase in the burden of 
depression (Abraham et al., 2021). Depression is a highly significant healthcare problem because it has direct causality on depreciation of physical health, thereby increasing medical costs incurred by the affected individual (Levine et al., 2016; Hossen et al., 2021). Depression in the UAE has a prevalence rate between $12.5-28.6 \%$, with women being the most affected than men (Razzak et al., 2019).

Doctors and nurses who spend their entire lives tending to patients oftentimes suffer in silence. According to Gong et al. (2014), depression among doctors and nurses hinders their professional performance and adversely impacts the quality of healthcare rendered. Comprehensive interventions aimed at optimizing their welfare will benefit the healthcare system and serve as a pivotal avenue to quality patient care. The multiple factors of depressive disorders and insufficient knowledge of their aetiology have hindered advances in the treatment and management of depression. With a plethora of different causes varying from individual to individual, personality has been hypothesized as a critical characteristic in predicting depression (Hakulinen et al., 2015).

Personality traits related to an individual's cognitive, emotional, and behavioral aspects are vital factors in considering their likelihood of gravitating towards depressive symptoms and other psychopathological states (Kim et al., 2016; Dan et al., 2021). The HEXACO personality model describes six fundamental characteristics defining different personalities (McKay \& Tokar, 2012). Multiple studies have been conducted to examine the implications of personality traits on professional life. UAE has limited research conducted in mental health topic areas and there is no existing research around the association between depression and personality traits. This research will fill the gap by providing new insights, through a quantitative cross-sectional survey study, into the implications of personality traits and socio-demographic factors on depression in the UAE at workplace, within doctors and nurses.

\section{LITERATURE REVIEW}

\section{Depression}

Depression refers to a persistent feeling of lack of interest or hopelessness, accompanied by loss of interest or pleasure in daily activities once considered pleasurable and low selfesteem that unfavorably disturbs an individual's personal and family life (Islam \& Adnan, 2017). Depression within the workplace is a common challenge that adversely impacts employees' functioning, which in turn, impacts the organizational performance (Yunus et al., 2019). It is reported to have significant economic impact on organizations, in indirect and direct costs. For instance, in America, 31\% of the depression costs relate to direct medical expenses, while the remaining 69\% result from lower employee productivity which is because of lost wages, absenteeism, and premature mortality (Stander et al., 2016). Usually, employers lose an estimate of 32 days of productivity per year from workers with depressive disorder (Williams et al., 2018).

\section{Depression in the Healthcare Industry}

Due to the demanding nature of work of healthcare professionals, psychological distress remains a common challenge among them (Maharaj, 2020). Several factors including long workhours, role-conflict, experiencing physical or verbal abuse by patients, emotional labor, and constant concern about medical litigation and errors expose healthcare professionals to psychological distress and depression (Kim et al., 2018). Depression among healthcare practitioners is a significant issue of concern since it is associated with 
increased medical errors and poor performance, consequently affecting the patients' health. Also, healthcare workers' mental health problems contribute to a high turnover rate (Kim et al., 2018). Consequently, this impacts the medical costs of healthcare institutions through reduced productivity and training costs. These effects put patients' health at risk. The challenge is augmented as doctors are largely hesitant to seek help for mental health concerns, leaving them feeling isolated and despondent.

Risk factors for depression among healthcare professionals are diverse and range from biomedical, genetic to socio-cultural and psychological (Hubbard et al., 2021; Ragi et al., 2021). For instance, Hubbard et al. (2021) and Rahman et al. (2020) established a significant positive relationship between depression and socio-demographic factors (gender, age, and deprivation). Islam and Adnan (2017) established a positive significant relationship between marital status and age with depression severity. Also, family income, gender, and education have a significant negative relationship with depression severity. However, Awan (2019) and Paz et al. (2020) established a significant positive relationship between gender and depression prevalence.

Overall, there is increasing risk among healthcare professionals and the effects of depression among them are severe. To improve management and reduce the level of depression, it is important to gain a comprehensive understanding of how various social-demographic factors influence mental health among healthcare workers in UAE. However, related studies are very limited. Besides, the results obtained by other scholars are inconsistent. Thus, there is need to examine the influence of different socio-demographic factors on depression severity among doctors and nurses. It was hypothesized that:

H1a: $\quad$ Socio-demographic factors can significantly predict depression among doctors and nurses in the UAE

H1b: Working hours is the most significant socio-demographic factor for predicting depression among doctors and nurses in the UAE

\section{Workplace Depression and Personality Traits}

Many studies have been undertaken to examine the implications of personality traits on a professional's life, ranging from job performance to mental health. Gramstad et al. (2013) established that neuroticism and reality weakness personality traits significantly predicted mental health problems among junior physicians, while the trait extraversion protected against depression symptoms. Furthermore, Hakulinen et al. (2015) established that low extraversion, alongside high neuroticism and low conscientiousness, resonated with higher probabilities of developing depressive symptoms.

Personality traits have also been hypothesized to mediate the association between workrelated stress factors and depression. Parent-Lamarche and Marchand (2019) established that specific personality traits encompassing self-esteem and locus of control, alongside general traits of openness, extraversion, and conscientiousness, efficiently moderate the association between working conditions, job insecurity and depression.

\section{HEXACO Trait Theory}

HEXACO personality trait dimensions are an upgrade to the Five-Factor Model personality. Soto et al. (2015) define the Five-Factor Model (FFM) personality traits as five main dimensions of human personality: extraversion, agreeableness, conscientiousness, emotionality, and openness. HEXACO model adds Humility-Honesty to FFM, and has 
shown more replicable results in personality studies, (McKay \& Tokar, 2012) and displays better predictive capabilities in psychological well-being (Aghababaei \& Arji, 2014).

Lee and Ashton (2020) further reclassified HEXACO factors into two groups based on conceptual interpretation. Extraversion, conscientiousness and openness form the group of traits thought to produce distinctions in individual interactions in social, workplace, and creative spaces (Lee \& Ashton, 2020). Each trait has a significant evolutionary advantage to an individual and comes with a disadvantage in some other facets. High extraversion accounts for the successful formation of networks and increased chances of mating (Lukaszewski, 2020). However, extraversion significantly increases the amount of energy used by the individual and predisposes them to undue competition for attention (Lee \& Ashton, 2020). Conscientiousness is associated with increased strategizing capabilities and the ability to plan for future but increased energy consumption in high-paced and highrisk environments that require immediate attention (Roberts et al., 2014). Openness is associated with exploration and the ability to willingly risk safety for thrill of making discoveries, such as new food sources, better economic opportunities, moving and settling in new environments; involving high mental effort required to make such decisions effectively (Deyoung et al., 2014).

The second group of HEXACO factors contains honesty-humility, agreeableness and emotionality (Lee \& Ashton, 2020). The group is responsible for individual differences that account for selfishness and altruism. Honesty-humility accounts for fairness, in which an individual chooses fairness and does not take advantage of others despite being able to (Johnson et al., 2011). High levels of honesty-humility lead to greater cooperation with others but lack gains acquired from exploiting others (Johnson et al., 2011). Agreeableness accounts for the ability of an individual to choose to be taken advantage of (Lee \& Ashton, 2020). High agreeableness also offers the opportunity for greater cooperation but predisposes an individual to exploitation. Emotionality regards how much an individual can prevent harm to themselves and members of their families. High emotionality corresponds to greater care for the individual and their kin and correlates to lost opportunities due to lower exposure to risk (Lee \& Ashton, 2020). Notably, most research have solely focused on the big five personalities with no specific focus on HEXACO personalities.

Although HEXACO framework is gaining popularity, the need for a sixth extensive trait, and nature of this variable are debatable. Many researchers (Saucier \& Ostendorf, 1999; Barford, Zhao, \& Smillie, 2015) posits that humility correlates strongly with agreeableness. Also, in the NEO-PI-R model (Trull et al., 1995), honesty-humility correlates significantly with straightforwardness and modesty facets of agreeableness, suggesting that any comprehensive facet-level model based on FFM could have similar predictive advantages (Anglim \& O'connor, 2019).

The whole trait theory defines the characteristics that identify a person as having a particular personality trait (Fleeson \& Jayawickreme, 2015), and diverse personalities have distinct distinguishing aspects which illustrate and identify them (Prentice, Jayawickreme \& Fleeson, 2019). Nurses and doctors, like other people, have varied personalities and work in fast-paced workplaces that need them to dedicate their lives to saving the lives of others (Liebenberg et al., 2018; Sun et al., 2017). As a result, their working atmosphere may be too taxing, leading to burnout and other undesirable consequences. As a result, the research study will use whole trait theory to conceptualize traits as nurses' and doctors' attributes, which differently predict depression. 
Based upon the literature reviewed, people with distinctive personality traits are likely to behave disparately in diverse situations. Therefore, it is important to understand how different personality traits influence depression among doctors and nurses to help devise effective strategies for managing depression among these populations. However, despite the high cases of depression among doctors and nurses in the Middle East, there is no study which examined how personality traits impact depression severity among doctors and nurses in the UAE.

Hence, it was hypothesized that:

H1a: $\quad$ Each trait predicts depression among doctors and nurses in the UAE.

H1b: Emotionality is the most significant trait in predicting depression among doctors and nurses in the UAE

\section{METHODS}

\section{Research Problem}

The main research problem is to establish the relationship between personality traits found in the HEXACO personality model and socio-demographic factors on depression amongst doctors and nurses.

\section{Research Variables}

HEXACO personality traits comprising of six variables: Honesty-Humility, Emotionality, Extraversion, Agreeableness, Conscientiousness, Openness to experience and six sociodemographic variables: gender, age, marital status, level of specialization, experience, working hours are the independent variables. Depression severity is the dependent variable.

\section{Population and Sampling}

The total sample included 331 doctors and nurses. This group of professionals is chosen for the study because the nature of their work demands enormous efforts and sacrifices emanating from long, late workhours and sleep deprivation (Liebenberg et al., 2018; Sun et al., 2017). Hence, they are highly susceptible to burnout and can provide information pertaining to depression. Snowball sampling was used. Participants' age ranging from 19 to 65 years and who had over three years of work experience in UAE were included in the study. This is because of the age demographic of employed population in the UAE (FCSA, 2019), also, nurses and doctors with three and above years of experience are deemed to have sufficient experience in their work environment and how it affects their lives. A total of 170 participants were selected after data cleaning. Demographics of the 170 respondents are summarized in Table 1 below.

Table 1: Demographics Analysis

\begin{tabular}{|l|l|l|l|}
\hline & & Frequency & Valid Percent \\
\hline Gender & Male & 62 & 36.5 \\
\hline & Female & 108 & 63.5 \\
\hline Age & Under 25 & 1 & 0.6 \\
\hline & $25-34$ & 49 & 28.8 \\
\hline & $35-44$ & 67 & 39.4 \\
\hline & $45-54$ & 43 & 25.3 \\
\hline
\end{tabular}




\begin{tabular}{|l|l|l|l|}
\hline & $55-65$ & 10 & 5.9 \\
\hline Marital Status & Single & 24 & 14.1 \\
\hline & Married & 141 & 82.9 \\
\hline & Divorced & 2 & 1.2 \\
\hline & Separated & 1 & 0.6 \\
\hline & Widowed/Widower & 2 & 1.2 \\
\hline & Doctor & 105 & 62.1 \\
\hline & Nurse & 64 & 37.9 \\
\hline Level of specialisationsion & Registrar & 9 & 5.3 \\
\hline & Specialist & 73 & 42.9 \\
\hline & Consultant & 13 & 7.6 \\
\hline & Assistant Nurse & 13 & 7.6 \\
\hline & Registered nurse & 40 & 23.5 \\
\hline & Nursing Supervisor & 5 & 2.9 \\
\hline & Others & 17 & 10 \\
\hline Work Experience & 3-6 years & 30 & 17.6 \\
\hline & 6-10 years & 47 & 27.6 \\
\hline & 10 years and above & 93 & 54.7 \\
\hline Working Hours & Below 48 hours & 24 & 14.1 \\
\hline & $48-55$ hours & 123 & 72.4 \\
\hline & 55-65 hours & 18 & 10.6 \\
\hline & More than 65 hours & 5 & 2.9 \\
\hline
\end{tabular}

\section{Instrumentation and Measures}

Self-administered version of the nine-item Patient Health Questionnaire-9 (PHQ-9) screening questionnaire (Anderson et al., 2002) was used to evaluate depression. Participants were instructed to indicate how often the symptoms troubled them during past two weeks for every item. The response scores for each item ranged from $0=$ "not at all" to $3=$ "nearly every day". The aggregate score (range 0 to 27 ) identified the depression severity, with scores of $\geq 5, \geq 10$, and $\geq 15$ suggesting mild, moderate, and severe depression, respectively.

Presence of depressive symptoms was defined as having a total score of one and above (Kroenke et al., 2001). PHQ-9 demonstrated a high-reliability coefficient of Cronbach's $\alpha$ in different studies, such as 0.89 in Primary Care and 0.86 on obstetrics-gynaecology studies (Kroenke et. al., 2001). Depressed mood, loss of interest, sleep disturbance, appetite disturbance, loss of energy, and feelings of worthlessness, difficulty concentrating, psychomotor retardation, and suicidal thoughts were the items that were addressed by PHQ-9 (Anderson et al., 2002; Manavalan, 2021).

A 60-item version of self-reporting HEXACO-60 questionnaire was used for accessing participants' personality traits (Lee \& Ashton, 2004). 10-items were assigned to each of the 6 HEXACO domains: Honesty-Humility, Emotionality, Extraversion, Agreeableness, Conscientiousness, and Openness to experience. Responses were collected on a scale from $1=$ strongly disagree to 5=strongly agree. After applicable item score reversal, each trait scores were calculated as the mean of constituting items. The internal consistency reliabilities ranged from .73 to .80, and correlations between long and short form range from .83 to .92 in a community sample (Ashton \& Lee, 2009). A six-item sociodemographic questionnaire was adopted from Hughes et al. (2016). 


\section{Procedure}

The study was approved by the university ethics committee prior to the survey. The study participation was entirely voluntary, and participants were free to withdraw at any time. All data was collected anonymously, with respondents providing a unique code if they wished to withdraw their data from the study. Participant information sheet and informed consent form were given before respondents could progress to the full survey. If consent was not agreed, respondents were taken straight to close the survey. A debrief page was provided with study details and support at the end of survey. Data was stored securely by the researcher. All ethical guidelines were followed.

Online Qualtrics (Qualtrics, Provo, UT) survey invitation link was shared through networks of healthcare professionals via messages, emails, WhatsApp, Facebook, and LinkedIn. Volunteered respondents were guided by simple questions to respond using the most appropriate answer to best of their knowledge (Basias \& Pollalis, 2018). The survey took approximately 20 minutes to complete, and data collection took two weeks.

\section{Analysis}

All data were exported from Qualtrics to SPSS 27.0 and statistical analysis were conducted. The dependent variable for the model was depression. Six HEXACO personality traits were continuous independent variables, and Pearson's correlations were performed. Six demographic characteristics were categorical independent variables; independent samples t-test and ANOVAs were conducted. The statistically significant variables were considered for predictors in the regression model. Post hoc test by Tukey was employed after a significant F-value was obtained to determine which groups significantly differed from one another. Multivariate assumption tests for normality, homoscedasticity, multi-collinearity, and outliers were performed and none were found, demonstrating the collected data was statistically fit for use in the inferential analysis. The study's reliability, which is its ability to represent entire population consistently, was maintained at or above Cronbach alpha of 0.7 .

\section{RESULTS}

\section{Data Screening and Cleansing}

To clean the data set, data screening was performed prior to data analysis. All the cases with partial responses and the variables that did not meet inclusion criteria were excluded from the data. There was a total of 170 valid cases for inclusion in the analysis.

\section{Descriptive Statistics}

The means and standard deviations for all study variables presented in the Table 2.

Table 2: Means and Standard Deviations

\begin{tabular}{|l|c|c|}
\hline & Mean & Std. Error \\
\hline Depression_severity & 7.6412 & 0.38764 \\
\hline Honesty_humility & 24.9588 & 0.40389 \\
\hline Emotionality & 26.6118 & 0.36618 \\
\hline Extraversion & 26.7647 & 0.40877 \\
\hline Agreeableness & 27.2647 & 0.39687 \\
\hline Conscientiousness & 25.4647 & 0.42282 \\
\hline Openness_to_experience & 27.8765 & 0.38895 \\
\hline
\end{tabular}




\section{Reliability Test}

Cronbach's alpha test was used to measure reliability of the questionnaire constructs for all variables. George and Mallery (2003) explicate that a coefficient $>.9$ is excellent, $>.8$ is good, .7 is acceptable, $>.6$ is questionable, $>.5$ poor, and $<.5$ is unacceptable. As per the study findings, depression severity had a coefficient of 0.824, Honesty-Humility (0.629), extraversion (0.714), Agreeableness (0.687), Conscientiousness (0.725), Openness to Experience (0.620), and Emotionality (0.586). Overall, all variables had a coefficient greater than 0.5 , thus indicating that all variables were reliable and could be used for inferential analysis.

\section{Inferential Statistics}

The research used correlation analysis to evaluate direction and strength of relationship between the level of depression among doctors and nurses with various personality traits. The results showed that Honesty-Humility $(\mathrm{r}=.328, \mathrm{p}=0.000)<0.01$, Emotionality $(\mathrm{r}=-.295$, $\mathrm{p}=0.000)<0.01$, Extraversion $(\mathrm{r}=.345, \mathrm{p}=0.000)<0.01$, Agreeableness $(\mathrm{r}=.036$, $\mathrm{p}=0.321)>0.01$, Conscientiousness $(\mathrm{r}=.183, \mathrm{p}=0.009)<0.01$ and Openness to Experience $(\mathrm{r}=$ $.047, \mathrm{p}=0.272)>0.01$.

Table 3: Correlations Analysis

\begin{tabular}{|c|c|c|c|c|c|c|c|c|}
\hline \multicolumn{9}{|c|}{ Correlations } \\
\hline & & $\begin{array}{c}\text { Depression_s } \\
\text { everity }\end{array}$ & $\begin{array}{l}\text { Honesty_hum } \\
\text { ility }\end{array}$ & Emotionality & Extraversion & $\begin{array}{l}\text { Conscientiou } \\
\text { sness }\end{array}$ & $\begin{array}{l}\text { Openness_to } \\
\text { _experience }\end{array}$ & $\begin{array}{c}\text { Agreeablene } \\
\text { ss }\end{array}$ \\
\hline \multirow[t]{3}{*}{ Depression_severity } & Pearson Correlation & 1 & $.328^{* *}$ & $-.295^{* *}$ & $.345^{* *}$ & $.183^{\star}$ & .047 & .036 \\
\hline & Sig. (2-tailed) & & .000 & .000 & .000 & .017 & .543 & .641 \\
\hline & $\mathrm{N}$ & 170 & 170 & 170 & 170 & 170 & 170 & 170 \\
\hline \multirow[t]{3}{*}{ Honesty_humility } & Pearson Correlation & $.328^{* *}$ & 1 & -.043 & .014 & $.327^{* *}$ & .120 & $.258^{*}$ \\
\hline & Sig. (2-tailed) & .000 & & .580 & .854 & .000 & .119 & .001 \\
\hline & $\mathrm{N}$ & 170 & 170 & 170 & 170 & 170 & 170 & 170 \\
\hline \multirow[t]{3}{*}{ Emotionality } & Pearson Correlation & $-.295^{* *}$ & -.043 & 1 & $-.225^{* *}$ & -.059 & -.024 & -.011 \\
\hline & Sig. (2-tailed) & .000 & .580 & & .003 & .447 & .756 & .885 \\
\hline & $\mathrm{N}$ & 170 & 170 & 170 & 170 & 170 & 170 & 170 \\
\hline \multirow[t]{3}{*}{ Extraversion } & Pearson Correlation & $.345^{* *}$ & .014 & $-.225^{* *}$ & 1 & $.345^{* *}$ & $.167^{*}$ & .151 \\
\hline & Sig. (2-tailed) & .000 & .854 & .003 & & .000 & .029 & .050 \\
\hline & $\mathrm{N}$ & 170 & 170 & 170 & 170 & 170 & 170 & 170 \\
\hline \multirow[t]{3}{*}{ Conscientiousness } & Pearson Correlation & $.183^{*}$ & $.327^{* *}$ & -.059 & $.345^{* *}$ & 1 & $.245^{* *}$ & .017 \\
\hline & Sig. (2-tailed) & .017 & .000 & .447 & .000 & & .001 & .826 \\
\hline & $\mathrm{N}$ & 170 & 170 & 170 & 170 & 170 & 170 & 170 \\
\hline \multirow{3}{*}{$\begin{array}{l}\text { Openness_to_experienc } \\
\mathrm{e}\end{array}$} & Pearson Correlation & .047 & .120 & -.024 & $.167^{*}$ & $.245^{* *}$ & 1 & -.027 \\
\hline & Sig. (2-tailed) & .543 & .119 & .756 & .029 & .001 & & .723 \\
\hline & $\mathrm{N}$ & 170 & 170 & 170 & 170 & 170 & 170 & 170 \\
\hline \multirow[t]{3}{*}{ Agreeableness } & Pearson Correlation & .036 & $.258^{* *}$ & -.011 & $.151^{*}$ & .017 & -.027 & 1 \\
\hline & Sig. (2-tailed) & .641 & .001 & .885 & .050 & .826 & .723 & \\
\hline & $\mathrm{N}$ & 170 & 170 & 170 & 170 & 170 & 170 & 170 \\
\hline
\end{tabular}

**. Correlation is significant at the 0.01 level (2-tailed).

*. Correlation is significant at the 0.05 level (2-tailed).

\section{Hypothesis Testing}

H1a: $\quad$ Each trait predicts depression among doctors and nurses in the UAE.

H1b: Emotionality is the most significant trait in predicting depression among doctors and nurses in the UAE

Multiple regression analysis was performed to determine whether each personality trait predicts depression among doctors and nurses in the UAE. Based on correlational 
analyses, only significantly associated HEXACO variables: Emotionality, HonestyHumility, and Extraversion, were included in the model. The model summary reported that $R$ was 0.518 and Adjusted $R$ square was 0.255 . The ANOVA results were $F(3,166)$ $=20.271$, and $p=0.00$ for depression measure at the significance level of 0.05 . After examining the actual effect of each of personality traits on depression severity, findings showed that Honesty-humility $(\beta=0.302, t=4.741, p$-values $<0.05)$ was the strongest predictor, while extraversion was the second strongest predictor. Emotionality was the least strong predictor $(\beta=.227, \mathrm{t}=4.292$, $\mathrm{p}$-values $<0.05)$.

Hypothesis 1a is partially supported as three traits - Honesty-Humility, Emotionality, and Extraversion, were found to have some significant predictive abilities of depression, whereas Agreeableness, Conscientiousness and Openness to Experience were not. Comparing the regression model results, it was found that emotionality is not the most significant trait in predicting depression among doctors and nurses; thus, Hypotheses $1 \mathrm{~b}$ was rejected.

H2a: $\quad$ Socio-demographic factors can significantly predict depression among doctors and nurses in the UAE

H2b: Working hours is the most significant socio-demographic factor for predicting depression among doctors and nurses in the UAE

Since socio-demographic factors were categorical variables, an independent $t$-test and oneway ANOVA tests were performed to determine if they were significant predictors of depression. Findings of independent t-test performed for gender was statistically significant $(\mathrm{t}(168)=-2.59, \mathrm{p}<0.01)$ indicating female doctors and nurses $(\mathrm{M}=8.39, \mathrm{SD}=4.95)$ experience more depression than male group $(\mathrm{M}=6.33, \mathrm{SD}=5.01)$.

Table 4: Independent Samples Test

\begin{tabular}{|l|c|c|c|c|c|}
\hline & \multicolumn{2}{|c|}{$\begin{array}{c}\text { Levene's Test for } \\
\text { Equality of Variances }\end{array}$} & \multicolumn{3}{|c|}{ t-test for Equality of Means } \\
\hline & F & Sig. & t & df & Sig. (2-tailed) \\
\hline Equal variances assumed & 0.285 & 0.594 & -2.588 & 168 & 0.01 \\
\hline Equal variances not assumed & & -2.579 & 125.796 & 0.011 \\
\hline
\end{tabular}

\section{ANOVA Test}

The ANOVA results for age were $F(4,165)=5.421, p=0.000$, showing a significant difference in age groups (under 25; 25-34; 35-44; 45-54; 55-64; 65 and above) and depressive symptoms.

ANOVA results for work experience years indicated that $F(1,167)=4.767, p<0.01$, demonstrating a significant difference in tenure groups (below 3 years; 3-6 years; 6-10 years; 10 years and above) and depressive symptoms. Individuals with three to six years of experience have a significantly higher depression levels (Mean=10.2, SD=5.45), than the groups with 6-10 years of work experience (Mean=8.60, SD=5.32), and over 10 years of work experience (Mean=6.33, $\mathrm{SD}=4.37)$.

Working hours findings were $\mathrm{F}(3,166)=2.771, \mathrm{p}<0.01$, showed a fairly significant difference in working hour groups (below 48 hours; 48-55 hours; 55-65 hours; more than 65 hours) and depressive symptoms. Post hoc results indicated that individuals who work for more than 60 hours have significantly higher depression levels (Mean=13.6, SD=4.51) than the groups with less than 48 working hours (Mean=8.17, SD=6.47), 48-55 hours of 
working (Mean=7.24, SD=4.74), and those with 55 to 65 working hours (Mean=8.00, $\mathrm{SD}=4.37)$.

Marital status findings were $\mathrm{F}(4,166)=0.272$, $\mathrm{p}>0.01$, which showed an insignificant difference in marital status groups (single, married, divorced, separated, widowed/widower). Additionally, the level of specialization findings was $\mathrm{F}(6,164)$ $=0.589, \mathrm{p}>0.01$, showing an insignificant difference in the level of specialization groups.

Based on the t-test and ANOVA results, it was established that gender, age, working hours, and work experience were significant predictors of depression. However, marital status and level of specialization were insignificant predictors of depression. Therefore, hypothesis 2a was partially supported, and it was concluded that not all sociodemographic factors significantly predict depression among doctors in the UAE.

Comparing these findings, it was identified that working hours had less significance in predicting depression among doctors and nurses in the UAE, than other sociodemographic factors. Thus, hypothesis $2 \mathrm{~b}$ was rejected.

\section{Discussion}

The goal of this study was to determine the impact of personality traits and sociodemographic factors on depression among doctors and nurses in the UAE. Personality traits are known to contribute significantly towards cognitive and emotion vulnerability that influence the risk of having depressive disorder (Kim et al., 2016). The study's results revealed Honesty-Humility, Extraversion, and Conscientiousness personality traits and level of depression among doctors and nurses is positive and significant, while emotionality and depression have a significant negative relationship. These findings are consistent with those of previous studies (Hakulinen et al., 2015; Kim et al., 2016; ParentLamarche \& Marchand, 2019). However, this study's findings differ with those of Gramstad et al. (2013) who established a negative relationship between extraversion and depression severity.

Khazanov \& Ruscio (2016) reveals negative emotionality is a common factor among depressed individuals and individuals who exhibit higher positive moods such as confidence, happiness, and energy are strong to deal with depressive situations. Therefore, this explains why emotionality has a positive significant negative relationship with depression severity in current study. However, higher extraversion is linked to positive sociality and emotionality, which in turn reduces depressive symptoms (Gubler et al., 2021) explaining findings of the current study. Leszko et al. (2020) reveals that conscientiousness is associated with having a positive emotional coping in relation to stressful situations. It involves assessing and modifying negative thoughts and shifting attention from negative thoughts to positive ones (Leszko et al., 2020). Furthermore, Bartley and Roesch (2011) urge that conscientiousness increases stress management ability to avoid stress, and stress tolerance. Thus, increased levels of conscientiousness are likely to reduce the depressive symptoms among doctors and nurses since stress management reduces the depression risk.

Honesty-Humility is found to be strongest predictor of depression. Ceschi et al. (2016) posits that people with low levels of Honesty-Humility are less inclined to feel and take care of job demands, which makes them to find an alternate work environment less distressing compared to their counterparts with high scores of Honesty-Humility. Since doctors and nurses work in a high-demanding job environment, those with low levels of 
Honesty-Humility are likely to find the job environment less distressing. Therefore, this explains why Honesty-Humility personality has significant positive relationship with depression severity among doctors and nurses. On a different note, Steele (2017) reveals that people with high levels of humility are likely to have adaptive qualities in their social relations. Therefore, this implies that high levels of Honesty-Humility may be attributed to reduced depression severity. Thus, there is a need to further examine whether humility is a significant positive predictor of depression severity.

Furthermore, this study's findings showed that the relationship between Agreeableness and Openness to Experience with depression was insignificant. Contrary, Kim et al. (2016) established a significant relationship between agreeableness and depression severity. The difference can be attributed to moderating variables including stress level that were included in Kim et al. (2016) study. Therefore, there is a need to further examine how moderator variables such as stress level impact the relationship between depression severity and personality traits. This study's findings also contradict with those of Van der Veen et al. (2017) who revealed that increased level of openness to experience has a significant negative relationship with depression. According to Van der Veen et al. (2017) openness to experience is associated with increased anxiety levels when no life-event has taken place in preceding year and that openness is characterized by intellectual curiosity, novelty-seeing, awareness of inner emotional states, and vivid imaginations. As such, high openness to experience may serve as a protective aspect when handling daily issues. Van der Veen et al. (2017) explains that this effect becomes insignificant when an individual is confronted with a real life-event. Hence, this may support the findings of this study and explain the insignificant relationship between openness to experience and depression severity.

It was expected that the relationship between agreeableness and depression would be significant since it contributes significantly to emotion cognitive and emotion vulnerability that influence the risk of having depressive disorder (Kim et al., 2016). Usually, individuals with low agreeableness are characterized by hostility, are more propensity for conflict, and antagonistic behaviors (Mongrain et al., 2018). Mongrain et al. (2018) further elucidate that individual with low agreeableness are less effective in dealing with interpersonal conflicts. Therefore, once these individuals are faced with interpersonal conflicts, they cannot manage them properly, which may lead them to experiencing high depressive symptoms.

This study findings show honesty-humility and agreeableness predict depression significantly differently which questions if both these dimensions should be treated as complementary as discussed in literature review.

Overall, findings of this study support the premise that different personality traits influence how individuals experience depression levels. Therefore, having a comprehensive understanding of factors that influence the levels of depression is essential for developing effective depression prevention and management strategies. Thus, this study's findings provide important insights that can help in the formulation of depression management strategies for doctors and nurses in UAE.

The socio-demographic factors findings revealed that age, gender, working hours, and work experience, significantly predict depression. The results indicated that gender was a significant predictor of depression. Depression demographics supports the finding; females are more likely to be depressed than males (Wright et al., 1989). Also, Nolen- 
Hoeksema's (1987) styles theory claims that women are more likely than males to ponder about their depressed symptoms, and that rumination leads to a higher relapse and severity, as well as a delayed recovery (Lyubomirsky et. al, 2015).

Whereas results for age indicated that age and depression have a significant positive relationship aligning with findings of Schaakxs et al. (2018) who established a significant relationship between age and depression. Nonetheless, the findings differ with those of Weiss Wiesel et al. (2015) who revealed that there is no significant relationship between age and depression. The positive significant relationship between age and depression severity may be explained by functionality ability and health-related issues (Sjöberg et al., 2017). Usually, aging process reduces the physical fitness of individuals, which adversely impacts their functionality ability (Milanović et al., 2013; Tomás et al., 2018). In this case, physical fitness includes one's agility, strength, flexibility, and endurance. When one's physical fitness is negatively impacted, this results to the person having difficulties in performing their normal daily activities (Milanović et al., 2013). Consequently, this increases their risk of getting depressive disorder. These findings are important for determining the retirement age for doctors and nurses, as it gives insights on age groups with increased levels of depression.

The ANOVA results indicated that work experience and workhours significantly predict depression. The findings are supported by Ogawa et al. (2018) who revealed that workhours significantly impact depression. So supporting these findings reveal that there exists significant moderate relationship between depression levels and workhours. Elbay et al. (2020) reveal that lesser work experience and more workhours are associated with higher depression scores. These findings can be associated with the fact that longworkhours expose doctors and nurses to more stress thus increasing their risk of depression (Koinis et al., 2015). In that vein, having a more experience means that a nurse or a doctor has been exposed to stressing situations more, consequently increasing their risk of developing depressive disorder.

Marital status and the level of specialization were insignificant predictors of depression severity. These findings are consistent with those of De Menil et al. (2012). However, the findings are contrary to findings of St John and Montgomery (2009), which reveal that there is a significant relationship between marital status and depression level. The researcher anticipated that marital status would be a significant predictor of depression. This is because single people are believed to be at a greater risk of depression due to lack of satisfaction enjoyed by married people (Al Khatib, 2013). More than $82 \%$ of the participants were married, which may have biased the findings to an uncertain extent.

This study's findings provide a comprehensive understanding of the socio-demographic factors that need to be put into consideration to protect the mental well-being of nurses and doctors, especially during this time of COVID-19 pandemic. Also, the existing literature concerning the impact of personality traits and socio-demographic factors on depression among doctors and nurses in the UAE is limited in scope. The findings of this study contribute to these areas of research thus providing future scholars with a wide literature to support their studies.

\section{Limitations of the Study}

Although the researcher strived to minimize errors in the study, there were few limitations that arose. Firstly, the study was limited to a single data collection technique, thus there was no triangulation of data. Secondly, generalization of the research findings to other 
populations may be limited as snowball sampling might not be representative. Thirdly, due to logistical reasons, some demographic and environmental factors about vulnerability variables potentially related to depression, including financial liability, ethnicity, early-life trauma, social and organizational support, were not studied. Also, the causality between depression and significant independent variables was not determined. Finally, social desirability may have influenced participants' responses to items, however the study's confidentiality and anonymity should have restricted this consequence to self-deception.

\section{CONCLUSION}

The main goal of this study was to determine the impact of personality traits and sociodemographic factors on depression among doctors and nurses in UAE. Study findings revealed that Honesty-Humility, Extraversion, and Conscientiousness, have a positive significant relationship with depression levels among doctors and nurses. However, emotionality has a negative significant relationship with depression severity. Besides, Agreeableness and Openness to Experience were found to have insignificant relationship with depression severity. With regards to the socio-demographic factors, research findings revealed that gender, age, working hours, and work experience are significant predictors of depression. But marital status and level of specialization were insignificant predictors of depression. However, mediation and moderation effects between variables needs to be studied.

\section{Recommendations}

Depression occurs at a relatively low proportion; expansive samples achieve only a small rate of depressed cases. However, 54\% from the initial sample were found to be depressed in the present study. The study brings awareness on prevalence and better understanding about depression among doctors and nurses in UAE, which could support policymakers, and researchers to develop efficient interventions for coping and reducing depression among doctors and nurses. Any predicted association identified in this study could be utilized in the implementation of employee recruitment, job crafting, positive psychology, and coaching.

\section{Future Research}

Future scholars should include participants from different geographical areas to enhance the generalization of the research findings. The study was a cross-sectional survey, and findings were based on self-report instruments, which reflected only on current psychological state at a specific point of time. Therefore, longitudinal and experimental studies with dynamic study designs including interviews and informant reports are recommended to gain a more detailed understanding of temporal and environmental factors affecting depression and to study its causation.

\section{REFERENCES}

Abraham, A., Chaabna, K., Doraiswamy, S., Bhagat, S., Sheikh, J., Mamtani, R., \& Cheema, S. (2021). Depression among healthcare workers in the Eastern Mediterranean Region: a systematic review and meta-analysis.Human resources for health, 19(1), 1-18. https://doi.org/10.1186/s12960-021-00628-6

Aghababaei, N., \& Arji, A. (2014). Well-being and the HEXACO model of personality. Personality and Individual Differences, 56, 139-142.

Al Khatib, S. A. (2013). Satisfaction with life, self-esteem, gender and marital status as predictors of depressive symptoms among United Arab Emirates college students. International Journal of Psychology and Counselling, 5(3), 53-61. 
Anderson, J. E., Michalak, E. E., \& Lam, R. W. (2002). Depression in primary care: Tools for screening, diagnosis, and measuring response to treatment. British Columbia Medical Journal, 44(8), 415419. https://bcmj.org/articles/depression-primary-care-tools-screening-diagnosis-andmeasuring-response-treatment

Anglim, J., \& O'connor, P. (2019). Measurement and research using the Big Five, HEXACO, and narrow traits: A primer for researchers and practitioners. Australian Journal of Psychology, 71(1), 16-25.

Awan, A. B. I. (2019). Relationship between the demographic variables and prevalence of depression among the university students. Biomedical Journal of Scientific \& Technical Research, 17(4), 12959-12961. http://dx.doi.org/10.26717/BJSTR.2019.17.003031

Barford, K. A., Zhao, K., \& Smillie, L. D. (2015). Mapping the interpersonal domain: Translating between the Big Five, HEXACO, and Interpersonal Circumplex. Personality and Individual Differences, 86, 232-237.

Bartley, C. E., \& Roesch, S. C. (2011). Coping with daily stress: The role of conscientiousness. $\begin{array}{llll}\text { Personality and individual } & \text { 79-83. }\end{array}$ https://dx.doi.org/10.1016\%2Fj.paid.2010.08.027

Basias, N., \& Pollalis, Y. (2018). Quantitative and qualitative research in business \& technology: Justifying a suitable research methodology. Review of Integrative Business and Economics Research, 7, 91-105. https://sibresearch.org/uploads/3/4/0/9/34097180/riber 7-s1 sp h17083_91-105.pdf

Ceschi, A., Sartori, R., Dickert, S., \& Costantini, A. (2016). Grit or honesty-humility? New insights into the moderating role of personality between the health impairment process and counterproductive work behavior. Frontiers in psychology, 7, 1799. https://doi.org/10.3389/fpsyg.2016.01799

Dan, Y., Ahmed, A.A.A., Chupradit, S., Chupradit, P.W., Nassani, A.A. and Haffar, M. (2021). The Nexus between the Big Five Personality Traits Model of the Digital Economy and Blockchain Technology Influencing Organization Psychology. Frontiers in Psychology, 12(780527), 1-12. https://doi.org/10.3389/fpsyg.2021.780527

De Menil, V., Osei, A., Douptcheva, N., Hill, A. G., Yaro, P., \& Aikins, A. D. G. (2012). Symptoms of common mental disorders and their correlates among women in Accra, Ghana: A populationbased survey. Ghana medical journal, 46(2), 95-103.

Deyoung, C. G., Quilty, L. C., Peterson, J. B., \& Gray, J. R. (2014). Openness to experience, intellect, and cognitive ability. Journal of Personality Assessment, 96(1), 46-52. https://doi.org/10.1080/00223891.2013.806327

Elbay, R. Y., Kurtulmuş, A., Arpacıoğlu, S., \& Karadere, E. (2020). Depression, anxiety, stress levels of physicians and associated factors in Covid-19 pandemics. Psychiatry research, 290, 113130. https://dx.doi.org/10.1016\%2Fj.psychres.2020.113130

FCSA, (2019). Federal Competitiveness \& Statistics Authority. https://fcsc.gov.ae/en-us

Fleeson, W., \& Jayawickreme, E. (2015). Whole trait theory. Journal of research in personality, 56, 82-92. https://doi.org/10.1016/j.jrp.2014.10.009

George, D., \& Mallery, M. (2003). Using SPSS for Windows step by step: a simple guide and reference.

Gong, Y., Han, T., Yin, X., Yang, G., Zhuang, R., Chen, Y., \& Lu, Z. (2014). Prevalence of depressive symptoms and work-related risk factors among nurses in public hospitals in southern China: A cross-sectional study. Scientific reports, 4(1), 1-5.

Gramstad, T. O., Gjestad, R., \& Haver, B. (2013). Personality traits predict job stress, depression and anxiety among junior physicians. BMC medical education, 13(1), 1-9. http://www.biomedcentral.com/1472-6920/13/150 
Gubler, D. A., Makowski, L. M., Troche, S. J., \& Schlegel, K. (2021). Loneliness and well-being during the Covid-19 pandemic: Associations with personality and emotion regulation. Journal of happiness studies, 22(5), 2323-2342. https://doi.org/10.1007/s10902-020-00326-5

Hakulinen, C., Elovainio, M., Pulkki-Råback, L., Virtanen, M., Kivimäki, M., \& Jokela, M. (2015). Personality and depressive symptoms: Individual participant meta-analysis of 10 cohort studies. Depression and anxiety, 32(7), 461-470. https://doi.org/10.1002/da.22376

Hossen, M. A., Zahir, E., Ata-E-Rabbi, H. M., Azam, M. A., and Rahman, M. H. (2021). Developing a Mobile Automated Medical Assistant for Hospitals in Bangladesh. 2021 IEEE World AI IoT Congress (AIIoT), 0366-0372, https://doi.org/10.1109/AIIoT52608.2021.9454236

Hubbard, G., den Daas, C., Johnston, M., \& Dixon, D. (2021). Sociodemographic and psychological risk factors for anxiety and depression: findings from the Covid-19 health and adherence research in Scotland on mental health (CHARIS-MH) cross-sectional survey. International journal of behavioral medicine, 1-13. https://doi.org/10.1007/s12529-021-09967-z

Hughes, J. L., Camden, A. A., \& Yangchen, T. (2016). Rethinking and updating demographic questions: Guidance to improve descriptions of research samples. Psi Chi Journal of Psychological Research, 21(3), 138-151.

Islam, M. R., \& Adnan, R. (2017). Socio-Demographic Factors and Their Correlation with the Severity of Major Depressive Disorder: A Population Based Study. World Journal of Neuroscience, 7(02), 193. https://doi.org/10.4236/wjns.2017.72014

Johnson, M. K., Rowatt, W. C., \& Petrini, L. (2011). A new trait on the market: Honesty-Humility as a unique predictor of job performance ratings. Personality and Individual Differences, 50(6), 857862. https://doi.org/10.1016/j.paid.2011.01.011

Khazanov, G. K., \& Ruscio, A. M. (2016). Is low positive emotionality a specific risk factor for depression? A meta-analysis of longitudinal studies. Psychological bulletin, 142(9), 991. https://dx.doi.org/10.1037\%2Fbul0000059

Kim, M. S., Kim, T., Lee, D., Yook, J. H., Hong, Y. C., Lee, S. Y., ... \& Kang, M. Y. (2018). Mental disorders among workers in the healthcare industry: 2014 national health insurance data. Annals of occupational and environmental medicine, 30(1), 1-8.

Kim, S. E., Kim, H. N., Cho, J., Kwon, M. J., Chang, Y., Ryu, S., ... \& Kim, H. L. (2016). Direct and indirect effects of five factor personality and gender on depressive symptoms mediated by perceived stress. PloS one, 11(4), e0154140. https://doi.org/10.1371/journal.pone.0154140

Koinis, A., Giannou, V., Drantaki, V., Angelaina, S., Stratou, E., \& Saridi, M. (2015). The impact of healthcare workers job environment on their mental-emotional health. Coping strategies: the case of a local general hospital. Health psychology research, 3(1). https://dx.doi.org/10.4081\%2Fhpr.2015.1984

Kroenke, K., Spitzer, R. L., \& Williams, J. B. W. (2001). The PHQ-9. Journal of General Internal Medicine, 16(9), 606-613. https://doi.org/10.1046/j.1525-1497.2001.016009606.x

Lee, K., \& Ashton, M. C. (2004). Psychometric properties of the HEXACO personality $\begin{array}{llr}\text { inventory. Multivariate behavioral } \quad \text { research, 39(2), 329-358. } & \end{array}$ https://doi.org/10.1207/s15327906mbr3902 8

Lee, K., \& Ashton, M. C. (2020). Encyclopedia of Personality and Individual Differences. Encyclopedia of Personality and Individual Differences, 1-6. https://doi.org/10.1007/978-3-319-28099-8

Leszko, M., Iwański, R., \& Jarzębińska, A. (2020). The relationship between personality traits and coping styles among first-time and recurrent prisoners in Poland. Frontiers in psychology, 10, 2969. https://doi.org/10.3389/fpsyg.2019.02969

Levine, D. S., Sripada, R. K., Ganoczy, D., Walters, H., Gorman, L. A., \& Valenstein, M. (2016). Poorer physical health is associated with greater mental health service utilization in a sample of depressed US Army National Guard soldiers. Military medicine, 181(8), 803-810.

Liebenberg, A. R., Coetzee, J. F. J., Conradie, H. H., \& Coetzee, J. F. (2018). Burnout among rural hospital doctors in the Western Cape: Comparison with previous South African studies. 
African journal of primary health care $\mathcal{E}$ family medicine, 10(1), 1-7. http://dx.doi.org/10.4102/phcfm.v10i1.1568

Lukaszewski, A. (2020). Encyclopedia of Personality and Individual Differences. In V. Zeigler-Hill \& T. K. Shackelford (Eds.), Encyclopedia of Personality and Individual Differences (Issue November). Springer International Publishing. https://doi.org/10.1007/978-3-319-28099-8

Lyubomirsky, S., Layous, K., Chancellor, J., \& Nelson, S. K. (2015). Thinking about rumination: The scholarly contributions and intellectual legacy of Susan Nolen-Hoeksema. Annual review of clinical psychology, 11, 1-22.

Maharaj, S. (2020). Stress, Anxiety, and Depression: Prevalence and Associations to Electroencephalography and Cognitive Performance in Healthcare Professionals (Doctoral dissertation).

Manavalan, M. (2021). Molecular Generators and Optimizers Failure Modes. Malaysian Journal of Medical and Biological Research, 8(2), 53-62. https://doi.org/10.18034/mjmbr.v8i2.583

McKay, D. A., \& Tokar, D. M. (2012). The HEXACO and five-factor models of personality in relation to RIASEC vocational interests. Journal of Vocational Behavior, 81(2), 138-149. https://doi.org/10.1016/j.jvb.2012.05.006

Milanović, Z., Pantelić, S., Trajković, N., Sporiš, G., Kostić, R., \& James, N. (2013). Age-related decrease in physical activity and functional fitness among elderly men and women. Clinical interventions in aging, 8, 549-556. https://dx.doi.org/10.2147\%2FCIA.S44112

Mongrain, M., Barnes, C., Barnhart, R., \& Zalan, L. B. (2018). Acts of kindness reduce depression in individuals low on agreeableness. Translational Issues in Psychological Science, 4(3), 323-334. https://www.researchgate.net/deref/http $\% 3 \mathrm{~A} \% 2 \mathrm{~F} \% 2 \mathrm{Fdx}$.doi.org\%2F10.1037\%2Ftps0000168

Nolen-Hoeksema, S. (1987). Sex differences in unipolar depression: evidence and theory. Psychological bulletin, 101(2), 259.

Ogawa, R., Seo, E., Maeno, T., Ito, M., Sanuki, M., \& Maeno, T. (2018). The relationship between long working hours and depression among first-year residents in Japan. BMC medical education, 18(1), 1-8. https://doi.org/10.1186/s12909-018-1171-9

Parent-Lamarche, A., \& Marchand, A. (2019). Work and depression: The moderating role of personality traits. Journal of Workplace Behavioral Health, 34(3), 219-239. https://doi.org/10.1080/15555240.2019.1614455

Paz, C., Mascialino, G., Adana-Díaz, L., Rodríguez-Lorenzana, A., Simbaña-Rivera, K., GómezBarreno, L., ... \& Ortiz-Prado, E. (2020). Behavioral and sociodemographic predictors of anxiety and depression in patients under epidemiological surveillance for COVID-19 in Ecuador. PLoS One, 15(9), e0240008.

Prentice, M., Jayawickreme, E., \& Fleeson, W. (2019). Integrating whole trait theory and self-determination theory. Journal of personality, 87(1), 56-69. https://doi.org/10.1111/jopy.12417

Qualtrics, Provo, UT, USA. https://www.qualtrics.com

Ragi, S., Rahman, M. H., Duckworth, J., Kalimuthu, J., Chundi P. and Gadhamshetty, V. (2021). Artificial Intelligence-driven Image Analysis of Bacterial Cells and Biofilms. ACM Transactions on Computational Biology and Bioinformatics, https://doi.org/10.1109/TCBB.2021.3138304

Rahman, M. M., Chowdhury, M. R. H. K., Islam, M. A., Tohfa, M. U., Kader, M. A. L., Ahmed, A. A. A., \& Donepudi, P. K. (2020). Relationship between Socio-Demographic Characteristics and Job Satisfaction: Evidence from Private Bank Employees. American Journal of Trade and Policy, 7(2), 65-72. https://doi.org/10.18034/ajtp.v7i2.492

Razzak, H. A., Harbi, A., \& Ahli, S. (2019). Depression: prevalence and associated risk factors in the United Arab Emirates. Oman medical journal, 34(4), 274.

Roberts, B. W., Lejuez, C., Krueger, R. F., Richards, J. M., \& Hill, P. L. (2014). What is conscientiousness and how can it be assessed? Developmental Psychology, 50(5), 1315-1330. https://doi.org/10.1037/a0031109 
Saucier, G., \& Ostendorf, F. (1999). Hierarchical subcomponents of the Big Five personality factors: A cross-language replication. Journal of Personality and Social Psychology, 76(4), 613-627.

Schaakxs, R., Comijs, H. C., Lamers, F., Kok, R. M., Beekman, A. T., \& Penninx, B. W. (2018). Associations between age and the course of major depressive disorder: a 2-year longitudinal cohort study. The Lancet Psychiatry, 5(7), 581-590. https://doi.org/10.1016/S22150366(18)30166-4

Sjöberg, L., Karlsson, B., Atti, A. R., Skoog, I., Fratiglioni, L., \& Wang, H. X. (2017). Prevalence of depression: Comparisons of different depression definitions in population-based samples of older adults. Journal of affective disorders, 221, 123-131.

Soto, C. J., Kronauer, A., \& Liang, J. K. (2015). Five-Factor Model of Personality. The Encyclopedia of Adulthood and Aging, 2(December 2015), 1-5. https://doi.org/10.1002/9781118521373.wbeaa014

St John, P. D., \& Montgomery, P. R. (2009). Marital status, partner satisfaction, and depressive symptoms in older men and women. The Canadian Journal of Psychiatry, 54(7), 487-492.

Stander, M. P., Korb, F. A., de Necker, M., de Beer, J. C., Miller-Janson, H. E., \& Moont, R. (2016). Depression and the Impact on Productivity in the Workplace: Findings from a South African Survey on Depression in the Workplace. J Depress Anxiety, 2(12), 1-8. http://dx.doi.org/10.4172/2167-1044.S2-012

Steele, J. R. (2017). Honesty-Humility as a Predictor of Wellness and Resiliency (Doctoral dissertation, Regent University).

Sun, J. W., Bai, H. Y., Li, J. H., Lin, P. Z., Zhang, H. H., \& Cao, F. L. (2017). Predictors of occupational burnout among nurses: a dominance analysis of job stressors. Journal of clinical Nursing, 26(2324), 4286-4292. https://doi.org/10.1111/jocn.13754

Tomás, M. T., Galán-Mercant, A., Carnero, E. A., \& Fernandes, B. (2018). Functional capacity and levels of physical activity in aging: a 3-year follow-up. Frontiers in medicine, 4, 244. https://doi.org/10.3389/fmed.2017.00244

Trull, T. J., Useda, J. D., Costa Jr, P. T., \& McCrae, R. R. (1995). Comparison of the MMPI-2 Personality Psychopathology Five (PSY-5), the NEO-PI, and the NEO-PI-R. Psychological Assessment, 7(4), 508.

van der Veen, D. C., van Dijk, S. D., Comijs, H. C., van Zelst, W. H., Schoevers, R. A., \& Oude Voshaar, R. C. (2017). The importance of personality and life-events in anxious depression: from trait to state anxiety. Aging \& mental health, 21(11), 1177-1183.

Wang, H., Naghavi, M., Allen, C., Barber, R. M., Bhutta, Z. A., Carter, A., ... \& Bell, M. L. (2016). Global, regional, and national life expectancy, all-cause mortality, and cause-specific mortality for 249 causes of death, 1980-2015: a systematic analysis for the Global Burden of Disease Study 2015. The lancet, 388(10053), 1459-1544.

Weiss Wiesel, T. R., Nelson, C. J., Tew, W. P., Hardt, M., Mohile, S. G., Owusu, C., ... \& Cancer Aging Research Group (CARG). (2015). The relationship between age, anxiety, and depression in older adults with cancer. Psycho-Oncology, 24(6), 712-717.

Williams, A. L., Parks, A. C., Cormier, G., Stafford, J., \& Whillans, A. (2018). Improving resilience among employees high in depression, anxiety, and workplace distress. Int J Manag Res, 9(1-2), 4-22.

Wright, F., O'Leary, J., \& Balkin, J. (1989). Shame, Guilt, Narcissism, and Depression: Correlates and Sex Differences. Psychoanalytic Psychology, 6(2), 217-230.

Yunus, W. M. A. W. M., Musiat, P., \& Brown, J. S. (2019). Evaluating the feasibility of an innovative self-confidence webinar intervention for depression in the workplace: A proof-of-concept study. JMIR mental health, 6(4), e1140 


\section{SECTION A: Demographics (please tick appropriately)}

1. Kindly indicate your gender identity
a) Male
b) Female

2. What is your age bracket?
a) Under 25
b) $25-34$
c) $35-44$
d) $45-54$
e) $55-64$
f) 64 and above

3. What is your marital status?
a) Single
b) Married
c) Divorced
d) Separated
e) Widowed/Widower

4. What is your profession? (Validation- Others will not be able to proceed)
a) Doctor
b) Nurse
c) Others

5. Are you currently working in the UAE? (Validation- 'No' cannot proceed)
a) Yes
b) No

4. What is your position in your health care institution?
a) Registrar
b) Specialist
c) Consultant
d) Assistant Nurse
e) Registered nurse
f) Nursing Supervisor
g) Others

5 . How long have you been working in a health care institution?
a) Below 3 years
b) 3-6 years
c) 6-9 years
d) 9 years and above

6. On average, how many hours do you work a week, including time at a hospital, in the field, or on call?
a) Below 48 hours
b) Between 48-53 hours
c) 58-63 hours
d) More than 63 hours

Source: (Hughes et al., 2016) 


\section{SECTION B: Depression}

Over the last two weeks, how often have you been bothered by any of the following problems?

Kindly rate on a scale of 0 to 3 on your level of agreement where $0=$ Not at all, $1=$ Several days, $2=$ More than half the days, $3=$ Nearly every day.

\begin{tabular}{|c|c|c|c|c|c|}
\hline & $\begin{array}{l}\text { How often do you experience any of the } \\
\text { following? }\end{array}$ & $\begin{array}{c}\text { Not } \\
\text { at all }\end{array}$ & $\begin{array}{c}\text { Several } \\
\text { days }\end{array}$ & $\begin{array}{l}\text { More than } \\
\text { half the days }\end{array}$ & $\begin{array}{c}\text { Nearly } \\
\text { every day }\end{array}$ \\
\hline & & 0 & 1 & 2 & 3 \\
\hline 1 & $\begin{array}{l}\text { Feeling depressed, sad, down, low, or } \\
\text { hopeless. }\end{array}$ & & & & \\
\hline 2 & Little interest or pleasure in doing things & & & & \\
\hline 3 & $\begin{array}{l}\text { Moving or speaking so slowly that other } \\
\text { people could have noticed? Or the opposite } \\
\text { - being so fidgety or restless that you have } \\
\text { been moving around a lot more than usual }\end{array}$ & & & & \\
\hline 4 & $\begin{array}{l}\text { Experiencing sleep disturbance where I have } \\
\text { difficulty falling asleep and staying asleep }\end{array}$ & & & & \\
\hline 5 & Poor appetite or overeating & & & & \\
\hline 6 & $\begin{array}{l}\text { Loss of energy or feeling tired or having little } \\
\text { energy }\end{array}$ & & & & \\
\hline 7 & $\begin{array}{l}\text { I am experiencing trouble concentrating on } \\
\text { things, such as reading the newspaper or } \\
\text { watching television }\end{array}$ & & & & \\
\hline 8 & $\begin{array}{l}\text { I am feeling bad about myself - or that I am a } \\
\text { failure or have let myself or my family down }\end{array}$ & & & & \\
\hline 9 & $\begin{array}{l}\text { I have thoughts that I would be better off } \\
\text { dead or of hurting myself in some way }\end{array}$ & & & & \\
\hline
\end{tabular}

Source: Kroenke, Spitzer, \& Williams (2001) 


\section{SECTION C: HEXACO Personality Traits}

Directions: Below you will find a series of statements about you. Please read each statement and decide how much you agree or disagree with that statement. Then click your response in the space next to the statement using the following scale:

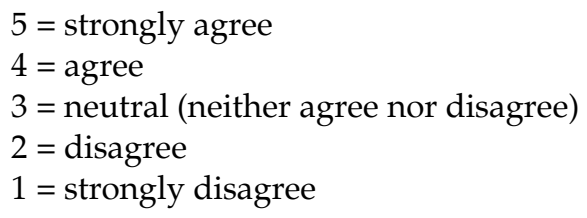

Please answer every statement, even if you are not completely sure of your response.

\begin{tabular}{|c|c|c|c|c|c|c|}
\hline & & 1 & 2 & 3 & 4 & 5 \\
\hline 1 & I would be quite bored by a visit to an art gallery. & & & & & \\
\hline 2 & $\begin{array}{l}\text { I plan ahead and organize things, to avoid scrambling at the } \\
\text { last minute. }\end{array}$ & & & & & \\
\hline 3 & $\begin{array}{l}\text { I rarely hold a grudge, even against people who have badly } \\
\text { wronged me. }\end{array}$ & & & & & \\
\hline 4 & I feel reasonably satisfied with myself overall. & & & & & \\
\hline 5 & $\begin{array}{l}\text { I would feel afraid if I had to travel in bad weather } \\
\text { conditions. }\end{array}$ & & & & & \\
\hline 6 & $\begin{array}{l}\text { I wouldn't use flattery to get a raise or promotion at work, } \\
\text { even if I thought it would succeed. }\end{array}$ & & & & & \\
\hline 7 & $\begin{array}{l}\text { I'm interested in learning about the history and politics of } \\
\text { other countries. }\end{array}$ & & & & & \\
\hline 8 & I often push myself very hard when trying to achieve a goal. & & & & & \\
\hline 9 & People sometimes tell me that I am too critical of others. & & & & & \\
\hline 10 & I rarely express my opinions in group meetings. & & & & & \\
\hline 11 & I sometimes can't help worrying about little things. & & & & & \\
\hline 12 & $\begin{array}{l}\text { If I knew that I could never get caught, I would be willing to } \\
\text { steal a million dollars. }\end{array}$ & & & & & \\
\hline 13 & $\begin{array}{l}\text { I would enjoy creating a work of art, such as a novel, a song, } \\
\text { or a painting. }\end{array}$ & & & & & \\
\hline 14 & $\begin{array}{l}\text { When working on something, I don't pay much attention to } \\
\text { small details. }\end{array}$ & & & & & \\
\hline 15 & People sometimes tell me that I'm too stubborn. & & & & & \\
\hline 16 & $\begin{array}{l}\text { I prefer jobs that involve active social interaction to those that } \\
\text { involve working alone. }\end{array}$ & & & & & \\
\hline 17 & $\begin{array}{l}\text { When I suffer from a painful experience, I need someone to } \\
\text { make me feel comfortable. }\end{array}$ & & & & & \\
\hline 18 & Having a lot of money is not especially important to me. & & & & & \\
\hline 19 & $\begin{array}{l}\text { I think that paying attention to radical ideas is a waste of } \\
\text { time. }\end{array}$ & & & & & \\
\hline 20 & $\begin{array}{l}\text { I make decisions based on the feeling of the moment rather } \\
\text { than on careful thought. }\end{array}$ & & & & & \\
\hline 21 & People think of me as someone who has a quick temper. & & & & & \\
\hline
\end{tabular}




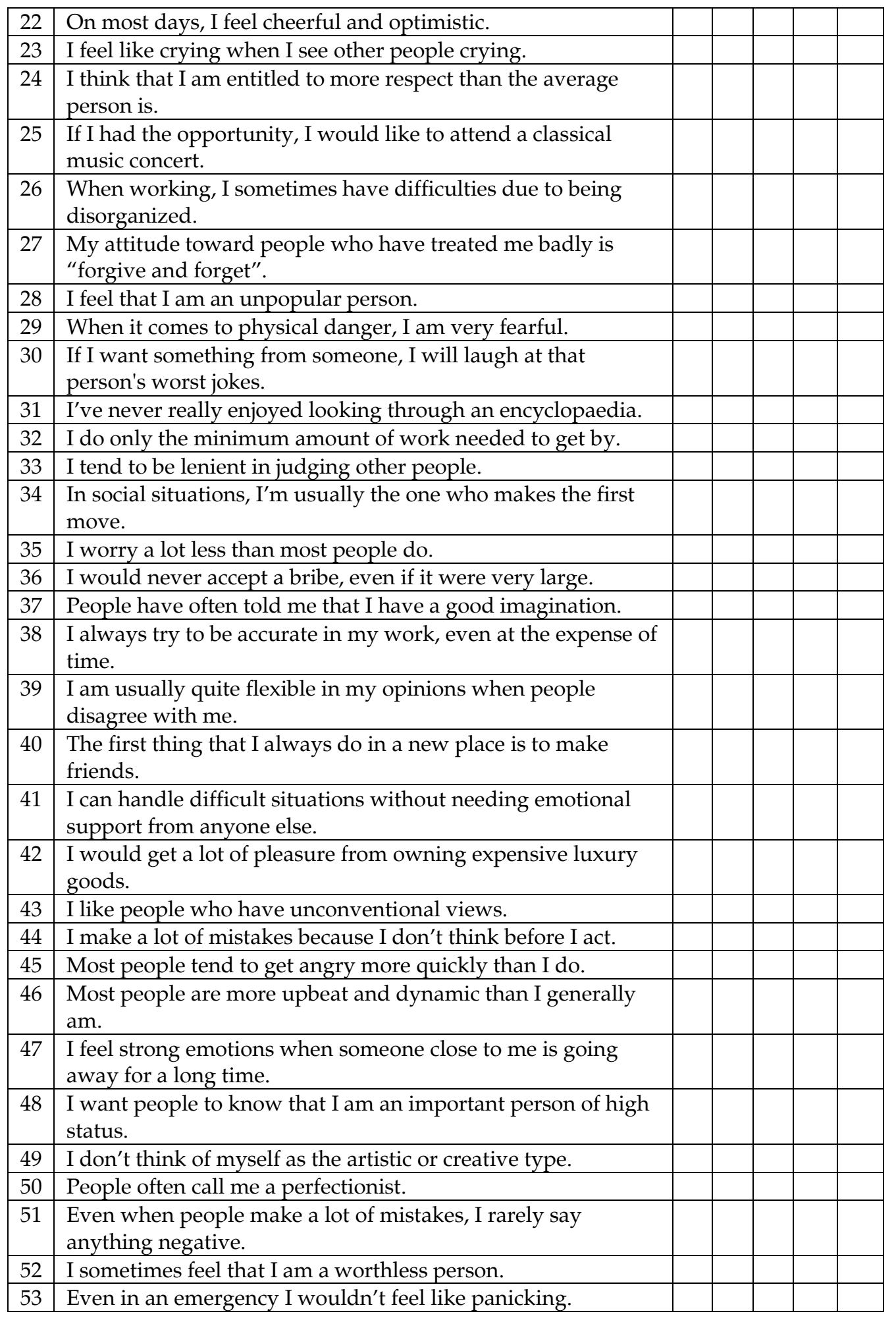




\begin{tabular}{|c|l|l|l|l|}
\hline 54 & $\begin{array}{l}\text { I wouldn't pretend to like someone just to get that person to } \\
\text { do favours for me. }\end{array}$ & & & \\
\hline 55 & I find it boring to discuss philosophy. & & & \\
\hline 56 & $\begin{array}{l}\text { I prefer to do whatever comes to mind, rather than stick to a } \\
\text { plan. }\end{array}$ & & & \\
\hline 57 & $\begin{array}{l}\text { When people tell me that I'm wrong, my first reaction is to } \\
\text { argue with them. }\end{array}$ & & & \\
\hline 58 & $\begin{array}{l}\text { When I'm in a group of people, I'm often the one who speaks } \\
\text { on behalf of the group. }\end{array}$ & & & \\
\hline 59 & $\begin{array}{l}\text { I remain unemotional even in situations where most people } \\
\text { get very sentimental. }\end{array}$ & & & \\
\hline 60 & $\begin{array}{l}\text { I'd be tempted to use counterfeit money, if I were sure, I } \\
\text { could get away with it. }\end{array}$ & & & \\
\hline
\end{tabular}

Source: Ashton \& Lee (2009) 